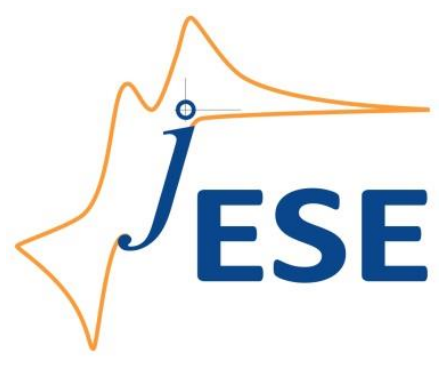

Open Access : : ISSN 1847-9286

www.jESE-online.org

Original scientific paper

\title{
Structural changes during the overoxidation of electro- chemically deposited poly(3,4-ethylenedioxythiophene) films
}

\author{
Mária Ujvári® , Győző G. Láng, Soma Vesztergom, Krisztina Júlia Szekeres, \\ Noémi Kovács, Jenő Gubicza* \\ Institute of Chemistry, Laboratory of Electrochemistry and Electroanalytical Chemistry, Eötvös \\ Loránd University, Pázmány P. s. 1/A, H-1117 Budapest, Hungary \\ *Institute of Physics, Department of Materials Physics, Eötvös Loránd University, \\ Pázmány P. s. 1/A, H-1117 Budapest, Hungary \\ ${ }^{\otimes}$ Corresponding Author: ujvari.maria@chem.elte.hu; Tel.: +36-1-372-2500/1201; Fax: +36-1-372-2592
}

Received: September 30, 2015; Accepted: November 23, 2015

\begin{abstract}
Electrochemical, mechanical and morphological properties of thin poly(3,4-ethylenedioxy-thiophene) (PEDOT) films deposited on gold were investigated in aqueous sulfuric acid and sodium sulphate solutions. At sufficiently positive electrode potentials overoxidation of the polymer took place and resulted in morphological changes and structure evolution. These effects were monitored by electrochemical impedance spectroscopy (EIS), scanning electron microscopy (SEM) and X-ray diffraction. Significant changes in the film stress caused by overoxidation were detected by using the electrochemical bending beam method. Results of the EIS measurements proved that the charge transfer process at the metal/film interface is more hindered in case of the degraded film. According to SEM images the overoxidation/degradation of PEDOT films can result in random-like but quite well-ordered arrays of islands and trench-like structures. The diffraction peaks of PEDOT became sharper and more intensive during the subsequent oxidation cycles indicating an increase in the degree of crystallinity of the polymer.
\end{abstract}

\section{Keywords}

Conducting polymers; PEDOT; Degradation; Delamination; Crystalline phase

\section{Introduction}

In recent years there has been considerable interest in the development of stable conjugated polymers because of their potential use in a variety of applications that require materials which 
are both electrically conducting and mechanically compliant. Electronic and electrochemical devices based on organic materials are e.g. light emitting diodes, sensors, actuators, organic thin film transistors, solar cells, memory devices, ion-selective electrodes, microelectrode arrays, fuel cells, etc. [1-15]. Obviously, in all these applications the long term stability of the polymer is of particular concern. This stability can be assessed in terms of the property of interest, such as: mechanical elasticity, conductivity, electrochemical activity, etc.

Poly(3,4-ethylenedioxythiophene) [16], often abbreviated as PEDOT, is relatively stable compared to other conducting polymers. The conjugated polymer backbone, consisting of alternating $\mathrm{C}-\mathrm{C}$ double bonds, provides for $\pi$-orbital overlap along the molecule. PEDOT can be doped with many anions, including macromolecular polyanions such as poly(styrene sulfonate) (PSS). Previous studies have shown that PEDOT is highly insoluble in most solvents, it is electroactive in aqueous solutions [17-19], and exhibits a relatively high conductivity. On the basis of these results studies have been performed to investigate the electrochemistry of PEDOT in more detail by using voltammetric techniques (in most cases cyclic voltammetry).

It has been found in Refs. [20-22] that at sufficiently positive electrode potentials, degradation ("overoxidation") of the polymer takes place. That is, when the positive potential limit of the cyclic voltammogram (CV) is extended to the region in which the overoxidation of the polymer film takes place, an oxidation peak (without a corresponding reduction peak) appears in the CV.

In Refs. [16] and [22] it has been shown that PEDOT films in modified electrodes undergo structural changes during the overoxidation (degradation) process. The most probable stages involved in the overoxidation/degradation process are: 1) Overoxidation results in stress generation in the PEDOT film [23]. 2) Formation of cracks due to internal stress. 3) The products of the degradation of the polymer leave the polymer layer. 4) After the formation of the line cracks, the film stress is partially released. 5) The partial delamination of the polymer layer leads to the exposure of the underlying metal substrate to the electrolyte solution.

It should be emphasized here that the polymer film still present on the substrate after overoxidation remains electroactive, and its internal structure may be an interesting subject for further studies, since according to literature reports conducting polymers in different overoxidation states show unique features useful for analytical, sensing and biomedical applications [24-27]. For instance, many studies have demonstrated that overoxidized polypyrrole films exhibit molecular-sieve properties, and such films have been used to fabricate glucose, alcohol, hydrazine, and dopamine sensors [25-32]. (Over)oxidized PEDOT films were successfully used for sensing perchlorate [33]. According to [34] overoxidized poly(3,4-ethylenedioxythiophene) film-modified screen-printed carbon electrodes exhibited superior sensitivity and selectivity to dopamine. However, the basis for the observed selectivity of overoxidized polymer films is not entirely clear $[32,35,36]$.

The purpose of the present paper is to complement (and extend) the results reported so far in the literature. In order to highlight some of the features mentioned above, PEDOT (poly(3,4-ethylenedioxythiophene)) films deposited on gold (and immersed in sulfate solutions) have been selected as illustrative examples.

\section{Experimental}

\section{Solutions and film preparation}

The Au/poly(3,4-ethylenedioxythiophene) films were prepared by galvanostatic deposition from $0.01 \mathrm{~mol} \mathrm{dm}^{-3}$ ethylenedioxythiophene (EDOT)/0.1 mol dm ${ }^{-3} \mathrm{Na}_{2} \mathrm{SO}_{4}$ solution on gold plates 
or on gold layers deposited by vacuum evaporation onto glass substrates. A constant current density of $0.2 \mathrm{~mA} \mathrm{~cm}^{-2}$ was applied for different time intervals, typically $1800 \mathrm{~s}$ or $7200 \mathrm{~s}$ (film thicknesses $d \approx 1.4 \mu \mathrm{m}$ and $d \approx 2.9 \mu \mathrm{m}$ ). An Autolab PGSTAT 20 potentiostat was used to control the electrochemical cell operations and data acquisition. The film thickness was estimated from the amount of charge passed during the deposition of the PEDOT film and by using the charge/film volume ratio determined earlier by direct thickness measurements $[1,37,38]$.

Analytical grade 3,4-ethylenedioxythiophene (Aldrich), p.a. $\mathrm{Na}_{2} \mathrm{SO}_{4}$ (Fluka), and ultra-pure water (specific resistance $18.3 \mathrm{M} \Omega \mathrm{cm}$ ) were used for solution preparation. The $0.1 \mathrm{M} \mathrm{H}_{2} \mathrm{SO}_{4}$ solutions used for voltammetric experiments were prepared with ultra-pure water, and p.a. $\mathrm{H}_{2} \mathrm{SO}_{4}$ (Merck). All solutions were purged with oxygen-free argon (Linde 5.0) before use and an inert gas blanket was maintained throughout the experiments.

\section{Cyclic voltammetry and impedance measurements}

The electrochemical tests were performed in conventional three-electrode electrochemical cells. A high surface area gold foil or a spiral shaped gold wire was arranged cylindrically around the working electrode to maintain a uniform electric field (counter electrode). A $\mathrm{NaCl}$ saturated calomel electrode (SSCE) was used as reference. Impedance measurements at different potentials were carried out using a Zahner IM6 system over a frequency range from $7.5 \mathrm{mHz}$ to $50 \mathrm{kHz}$. The impedance was measured at 60-80 discrete frequencies in the frequency region investigated during each scan at an amplitude of $10 \mathrm{mV}$.

\section{Stress change measurements}

The "bending beam" method [39-51] can be effectively used in electrochemical experiments, since the changes of the stress $\left(g_{\mathrm{f}}\right)$ in a thin film or other conducting layer on one side of an insulator (e.g. glass) strip in contact with an electrolyte solution can be estimated from the changes of the radius of curvature of the strip. If the potential of the electrode changes, electrochemical processes resulting in the change of $g_{\mathrm{f}}$ can take place exclusively on the metal side of the sample. The change in the film stress induces a bending moment and the strip bends. In case of a thin metal film on a substrate if the thickness of the film $\left(t_{f}\right)$ is sufficiently smaller than the thickness of the plate $\left(t_{\mathrm{s}}\right)$, i.e. $t_{\mathrm{s}}>t_{\mathrm{f}}$, the change of $g_{\mathrm{f}}$ can be obtained by an expression based on a generalized form of Stoney's equation [42,52]

$$
\Delta g_{\mathrm{f}}=k_{\mathrm{i}} \Delta(1 / R),
$$

where $k_{\mathrm{i}}$ depends on the design of the electrode. In most cases

$$
k_{\mathrm{i}}=\frac{E_{\mathrm{s}} t_{\mathrm{s}}^{2}}{6 t_{\mathrm{f}}\left(1-v_{\mathrm{s}}\right)},
$$

where $E_{\mathrm{s}}, v_{\mathrm{s}}$, and $R$ are Young's modulus, Poisson's ratio and radius of curvature of the plate, respectively. The values of $\Delta(1 / R)=\Delta g_{\mathrm{f}} / k_{\mathrm{i}}$ can be calculated if the changes of the deflection angle $\Delta \theta$ of a laser beam mirrored by the metal layer on the plate are measured using an appropriate experimental setup. The following approximate equation can be derived for large $R$ and $s$, and small $\theta[23,42,53-55]$ :

$$
\Delta\left(\frac{1}{R}\right) \approx \frac{\Delta \theta}{2 n_{s, a} h} \approx \frac{\Delta b}{2 n_{s, a} h l},
$$


where $h$ is the distance between the level of the solution in the cell and the reflection point of the laser beam (measured with the help of a cathetometer); $l$ is the distance between the electrode and the position sensitive photo detector (PSD), $\Delta b$ is the change of the position of the light spot on the PSD, and $n_{s, a}$ is the refractive index of the solution with respect to air. The refractive indexes were measured at $25.0^{\circ} \mathrm{C}$ with a Zeiss PR 2 refractometer and, based on the Cauchy parameters, the refractive index at $632.8 \mathrm{~nm}$ (see Table 1 in Ref. [22]) was calculated.

A He-Ne laser (Melles Griot 05-LHP-151, $1 \mathrm{~mW}$, operating at a wavelength of $632.8 \mathrm{~nm}$ ) was used in our electrochemical bending beam measuring system [43]. The displacement of the reflected beam $(\Delta b)$ was measured with a position-sensitive photodetector (PSD, Hamamatsu S1300). This device was attached to a signal processing unit (Hamamatsu C4757) that can provide analog output signals proportional to the coordinates of the incident light spot. The positionsensitive detector, the laser and the electrochemical cell were assembled on an optical bench in order to avoid vibrations.

Cantilever probes for the measurement of surface stress changes were made by evaporating a $150 \mathrm{~nm}$ thick gold layer on a very thin layer of titanium evaporated on one side of a glass plate (total length: $I_{\mathrm{s}}=60.0 \mathrm{~mm}$, width: $w_{\mathrm{s}}=5.0 \mathrm{~mm}$, thickness: $t_{\mathrm{s}}=147 \mu \mathrm{m}, E_{\mathrm{s}}=7.09 \cdot 10^{10} \mathrm{Nm}^{-2}$, $v_{\mathrm{s}}=0.230$ and $n_{\mathrm{g}}=1.522$, i.e. $k_{\mathrm{i}} \cdot t_{\mathrm{f}}=331.6 \mathrm{~N}$ for the present case) after careful cleaning of the surface of the substrate. An electrically isolated layer of the same metal covered the reverse side of the glass strip. This metal layer reflected the light of the He-Ne laser. The PEDOT film on the gold layers was made by the electropolymerization method described above. The geometrical area of the electrode (in contact with the solution) was $2.0 \mathrm{~cm}^{2}$.

The thermostated three-electrode electrochemical cell equipped with an optical window was driven by a battery-powered potentiostat (Jaissle Model 1001 T-NC). Control voltage was supplied by a function generator (Hewlett-Packard 3314A) or by a data acquisition card. A National Instruments 6034E DAC was used for the computer-based acquisition of the analog output signals of the PSD and the potentiostat. The software for controlling and data acquisition was developed in the National Instruments LabVIEW environment. All measurements were carried out at $25.0^{\circ} \mathrm{C}$.

\section{Scanning Electron Microscopy (SEM) and X-ray diffraction (XRD)}

The oxidation of the polymer film has been followed by a Quanta ${ }^{\mathrm{TM}}$ 3D FEG high-resolution, lowvacuum SEM/FIB instrument. A Philips Xpert powder diffractometer with CuKa radiation (wavelength: $0.15418 \mathrm{~nm}$ ) and Bragg-Brentano geometry [56] was used for the study of the phase structure of PEDOT by X-ray diffraction.

\section{Results and discussion}

Voltammetric measurements and stress change vs. electrode potential curves

Between -0.3 and $0.8 \mathrm{~V}$ vs. SSCE the oxidation-reduction process of the PEDOT films is reversible. Above $0.8 \mathrm{~V}$ potentials irreversible degradation of the polymer layer occurs as it can be seen in Fig. 1. A series of cyclic voltammetric curves recorded for the gold | PEDOT | $0.1 \mathrm{M}$ sulfuric acid (aq) electrode (geometric surface area: $4.0 \mathrm{~cm}^{2}$ ) at a sweep rate of $v=50 \mathrm{mV} \mathrm{s}^{-1}$ are presented in Fig. 1b. The potential program applied to the electrode is given in Fig. 1a. Three time intervals in Fig. 1 are marked by " $A$ ", " $B$ ", and " $C$ ". The voltammograms show capacitive behavior if the potential limit is kept below $0.8 \mathrm{~V}$. If the polarization potential exceeds this critical value an oxidation peak without corresponding reduction peak appears ("overoxidation cycles": see e.g. curves 2,4,6 in Fig. 1b). 
(a)

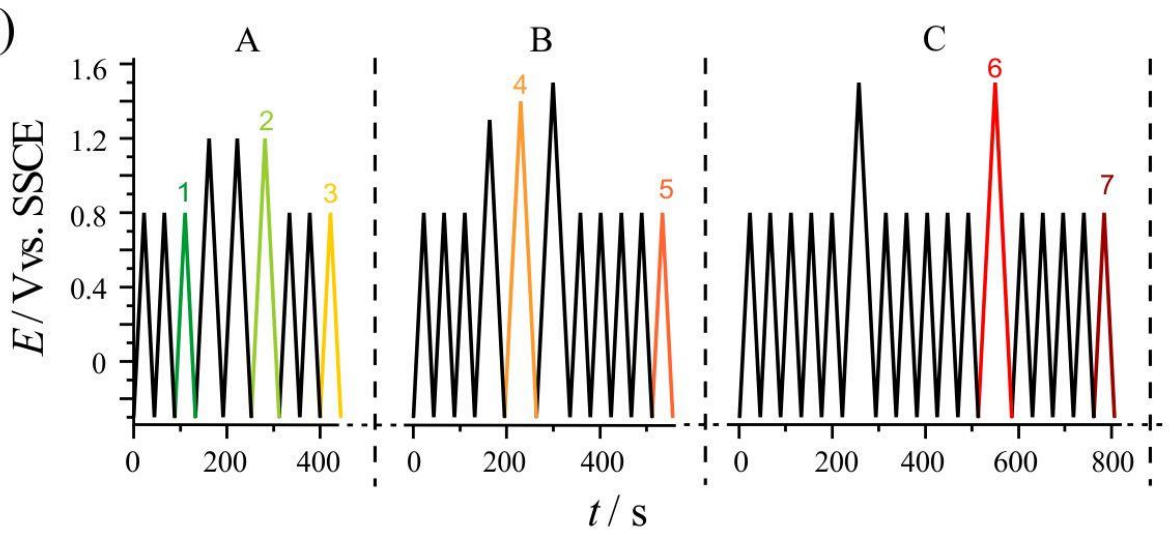

(b)

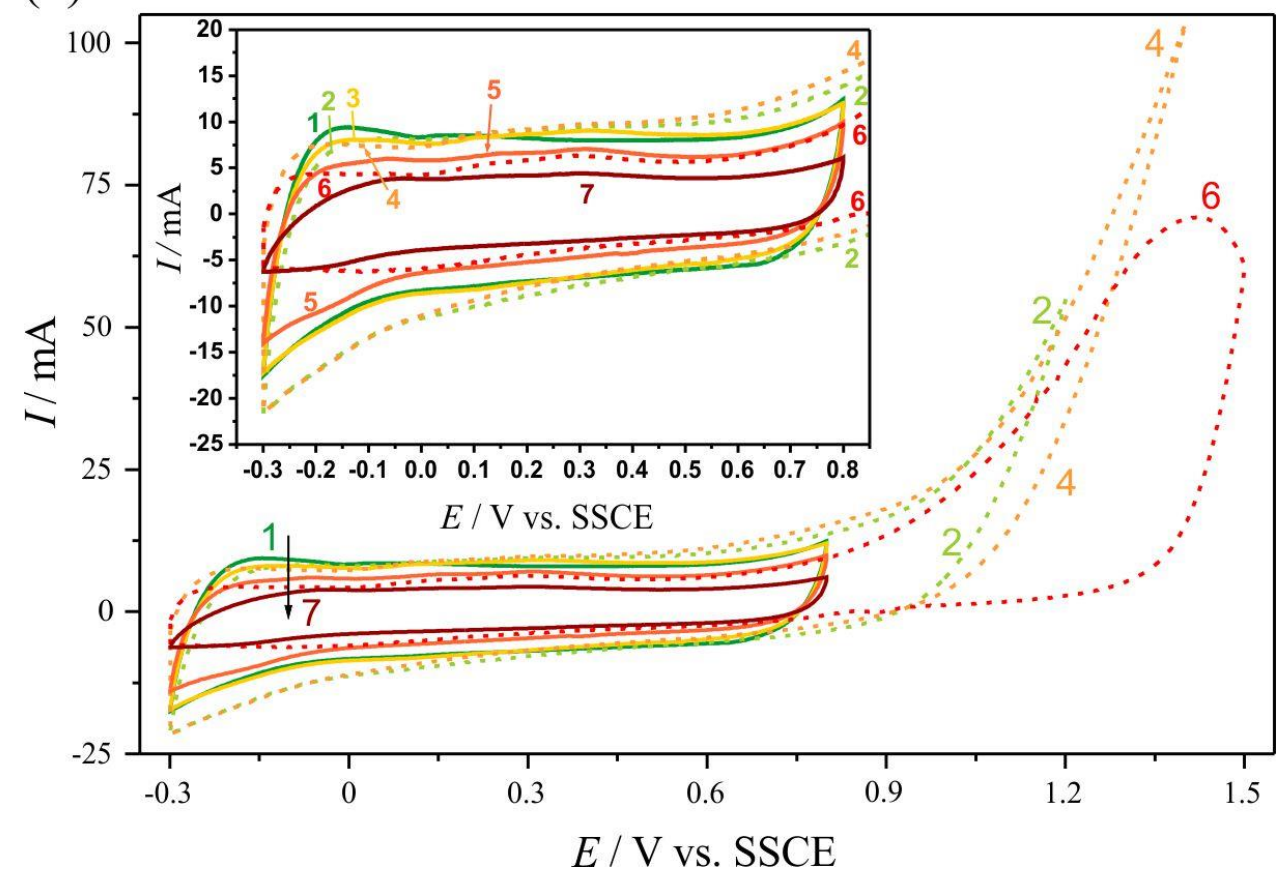

Figure 1. (a) Potential program applied to the AU / PEDOT / $0.1 \mathrm{M}$ sulphuric acid electrodes. Sweep rates: $v=50 \mathrm{mV} \mathrm{s}^{-1}$. " $A$ ", " $B$ " and " $C$ " are time intervals in which (b) the cyclic voltammetric curves (In the insert the "narrow-range" part is enlarged) were recorded $(d \approx 2.9 \mu \mathrm{m})$. E: electrode potential, t: time, I: current.

After oxidation up to $1.2 \mathrm{~V}$ there are only small differences between the voltammograms recorded in the $-0.3 \mathrm{~V}$ to $0.8 \mathrm{~V}$ ("narrow") potential range before and after overoxidation (curves 1 and 3 in Fig. 1b). Voltdeflectograms recorded under similar conditions are presented in Fig. 2 . The shape of the curves before and after mild oxidation are similar, but the change in $1 / R$ (between minimum and maximum) is slightly smaller.

If we extend the overoxidation limit up to $1.5 \mathrm{~V}$ vs. SSCE, the intensity of the capacitance of the film decreases (see curves 5 and 7 in Fig 1b), but curve 7 still shows the presence of the polymer in direct electrical contact with the gold surface. The shape of the $(1 / R)$ vs. $E$ curves changes considerably if the positive limit of the electrode potential is extended to $1.5 \mathrm{~V}$ vs. SCE (curves 5-7 in Fig. 2) and begins to resemble more and more that of the $(1 / R)$ vs. $E$ curve for bare Au.

As we have discussed in Ref. [22], the bending beam method offers the possibility to measure the changes of the stress in thin polymer films but the contributions from surface and bulk cannot be separated in the general case, therefore only the "voltdeflectograms", i.e. the $\Delta R^{-1}$ vs. $E$ plots are shown in Fig. 2. 


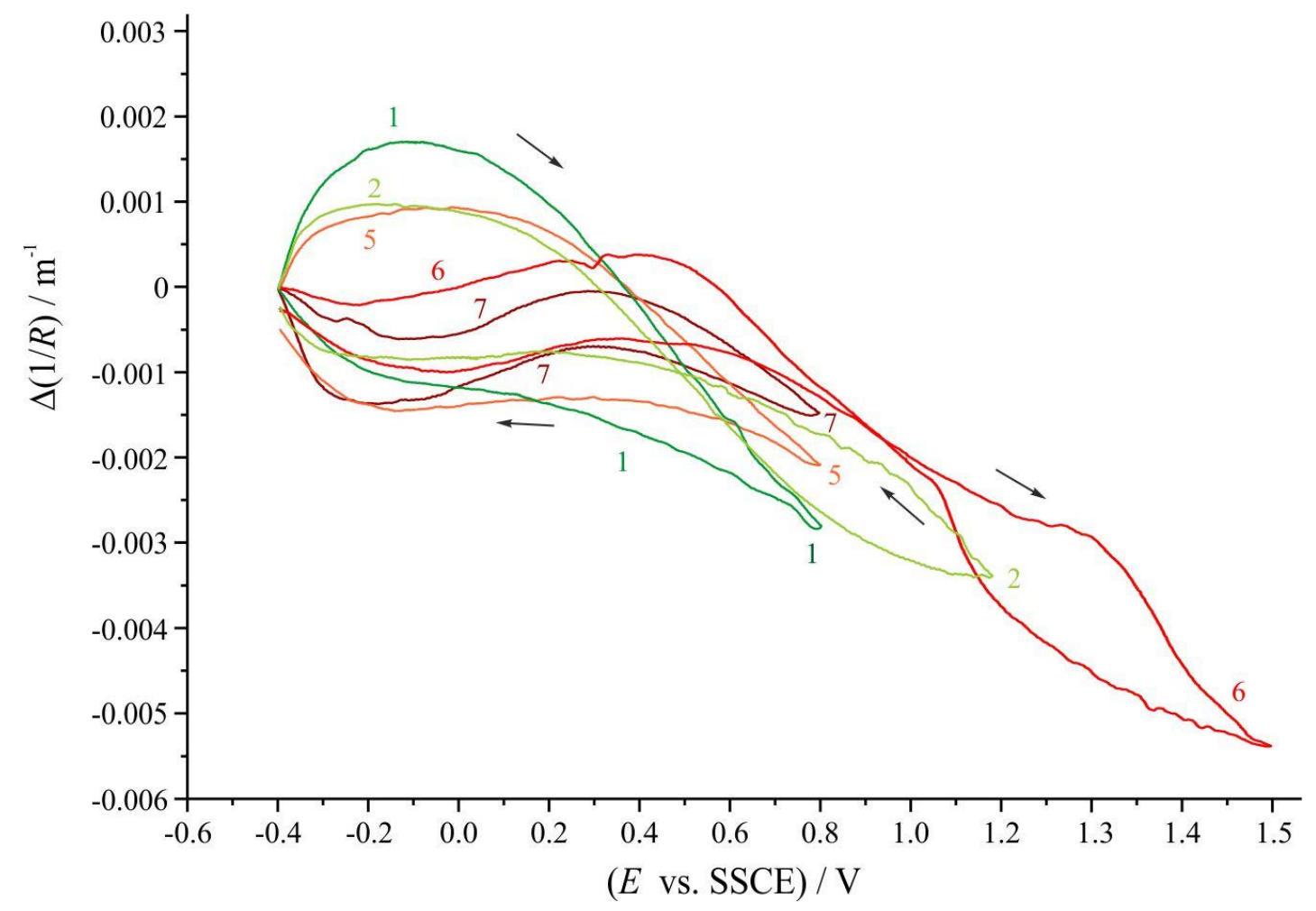

Figure 2. Voltdeflectograms recorded in time intervals " $A$ ", " $B$ " and " $C$ ". E: electrode potential, $R$ : radius of curvature of the cantilever $(d \approx 1.4 \mu \mathrm{m})$.

\section{Impedance measurements}

Impedance spectra of freshly prepared and overoxidized Au/PEDOT in $0.1 \mathrm{M} \mathrm{Na}_{2} \mathrm{SO}_{4}$ solution at $E=0.6 \mathrm{~V}$ are presented in Fig. 3. The impedances of freshly prepared electrodes at medium and low frequencies $(\omega<50 \mathrm{~Hz})$ can be well approximated in terms of a constant phase element (CPE):

$$
Z(\omega)=R_{\mathrm{u}}+\frac{1}{B}(\mathrm{i} \omega)^{-\alpha},
$$

where $\omega$ is the angular frequency, $R_{\mathrm{u}}$ is the uncompensated ohmic resistance, $B$ and $\alpha$ are the CPE parameters, and $\mathrm{i}$ is the imaginary unit. The values of $\alpha$ are close to unity. At higher frequencies an arc can be identified which can be observed more clearly in the spectra recorded after overoxidation (after repetitive cycling of the electrode potential between -0.3 and $1.5 \mathrm{~V}$ vs. SCE). The increase of the charge transfer resistance with the level of degradation is in accordance with the results for polypyrrole on Pt published in [57].

The decreasing capacitance and the increasing charge transfer resistance suggest that during (over)oxidation the electrochemical activity of the film decreases, and the charge transfer process at the metal/film interface becomes more hindered.

In [22] EQCM experiments have been carried out to evaluate the correlation between mass loss and electrochemical measurements. It has been shown during the potential cycling in the "stable region" the EQCM frequency changes periodically and the average remains practically the same.

When the positive (anodic) limit of the CV potential range was extended to $1.2 \mathrm{~V}$ a significant increase of the frequency was obtained indicating a mass decrease of the electrode during overoxidation of the polymer film. This can be attributed to the removal of oxidation products from the surface. 

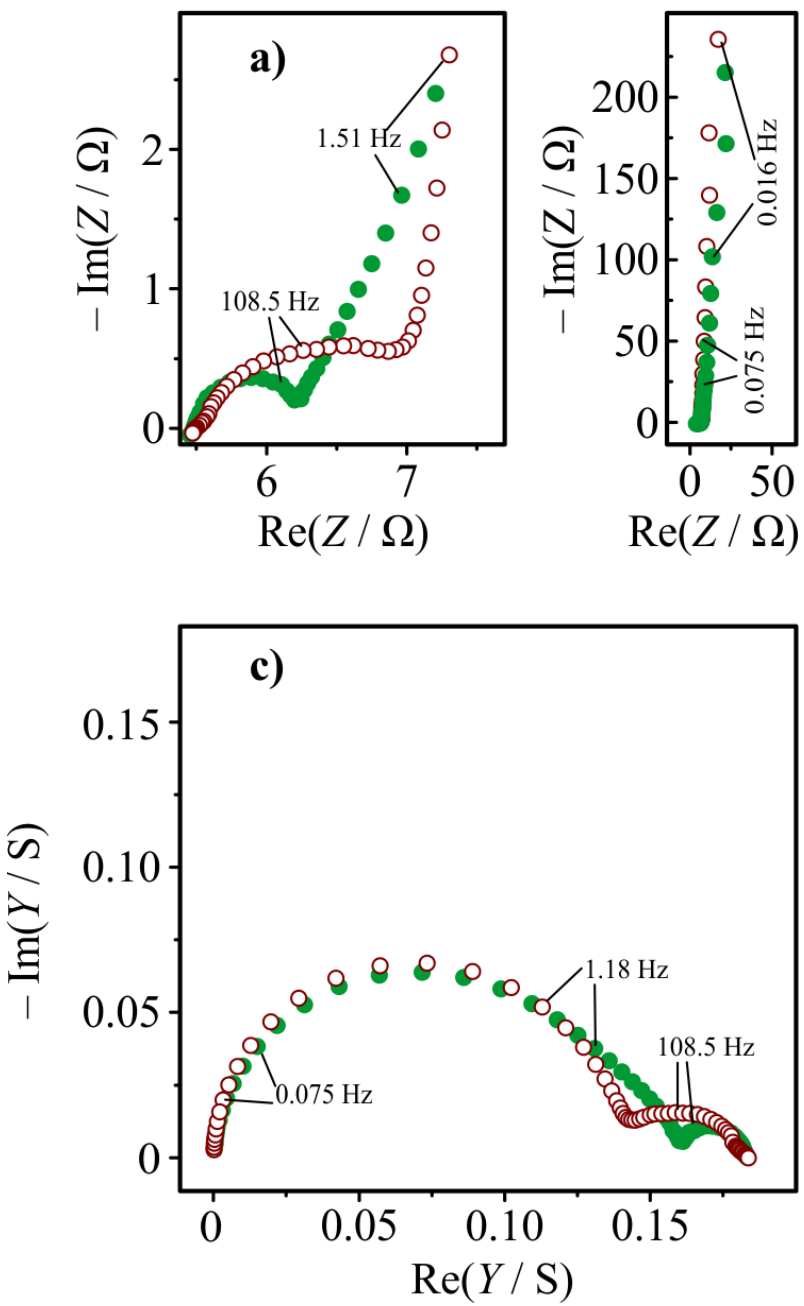
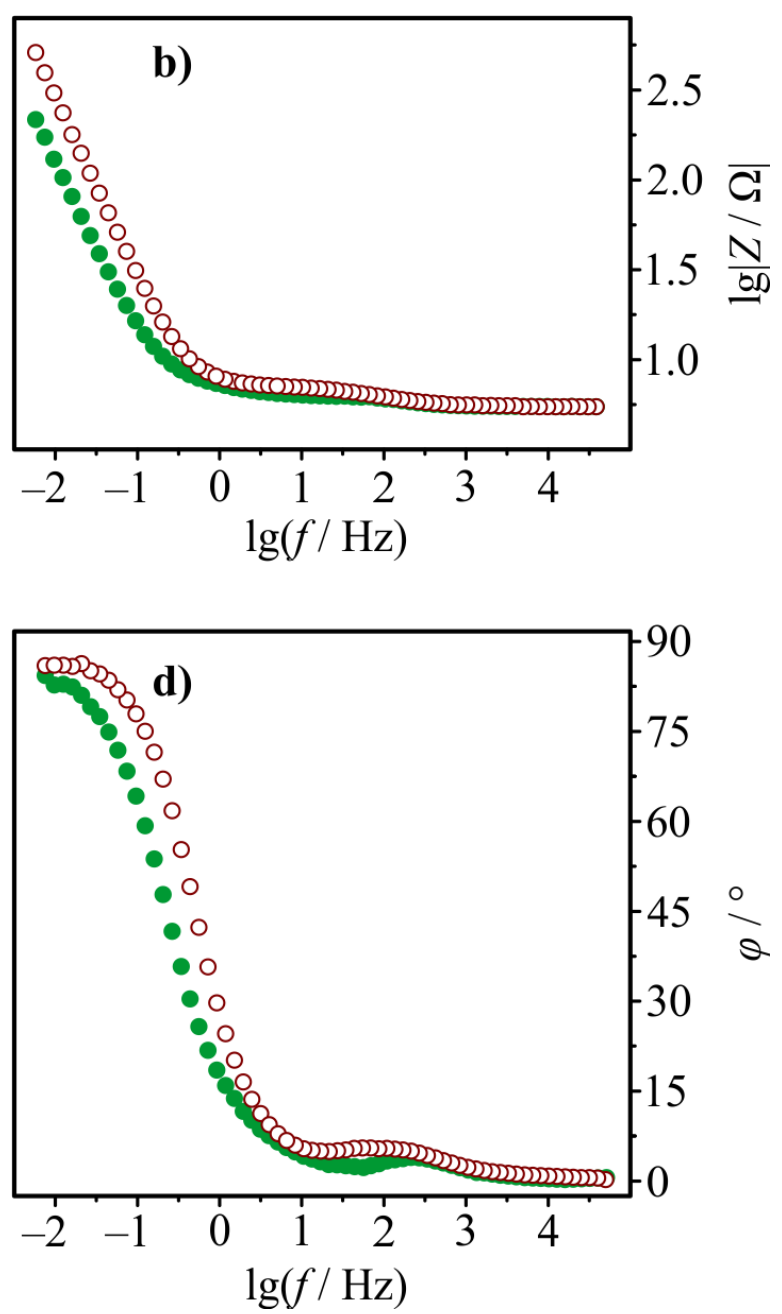

Figure 3. Impedance spectra (complex plane plots) $(a, c)$ and Bode plots (b,d) of Au/PEDOT in $0.1 \mathrm{M} \mathrm{Na}_{2} \mathrm{SO}_{4}$ solution at $E=0.60 \mathrm{~V}$ vs. SCE in case of freshly prepared (O) and overoxidized (O) film; ReZ, ImZ: real part and imaginary part of the complex impedance, respectively, $f:$ frequency, $\varphi$ : phase angle, $\operatorname{Re} Y, \operatorname{Im} Y: \operatorname{real}$ part and imaginary part of the complex admittance.

\section{Structure information: SEM micrographs and X-ray diffractograms}

The X-ray diffractogram and SEM images of the PEDOT film prepared freshly on gold are presented in Fig. 4. In the XRD spectrum a pattern characteristic for an amorphous state is identified. In the image detected by secondary electrons (SE) (Fig. 4a) well-separated globules (or cauliflower-like particles) are on the top of the polymer layer. The backscattered electron (BSE) micrograph taken from the same area (which characterizes a thicker layer compared to SE) shows that the globules are attached to an underlying smoother polymer layer (Fig. 4b).

In Fig. 5 X-ray diffractogram and SEM images of the polymer film after mild oxidation up to $1.2 \mathrm{~V}$ vs. SSCE (time interval " $A$ " in Fig. 2a) can be seen. The XRD spectrum is still characteristic for amorphous state but small peaks appear as sign of crystalline phase. The most striking difference between the micrograph (a) shown in Fig. 5 and that of the freshly prepared sample in Fig. 4a is the appearance of narrow cracks or crevices in the SEM image of the oxidized film. The cracks resulted in bright spots ("islands") in the backscattered SEM image (Fig. 5b). After further oxidation the XRD peaks corresponding to the crystalline polymer are growing (Fig. 6), the SEM images show interconnected crevices. 


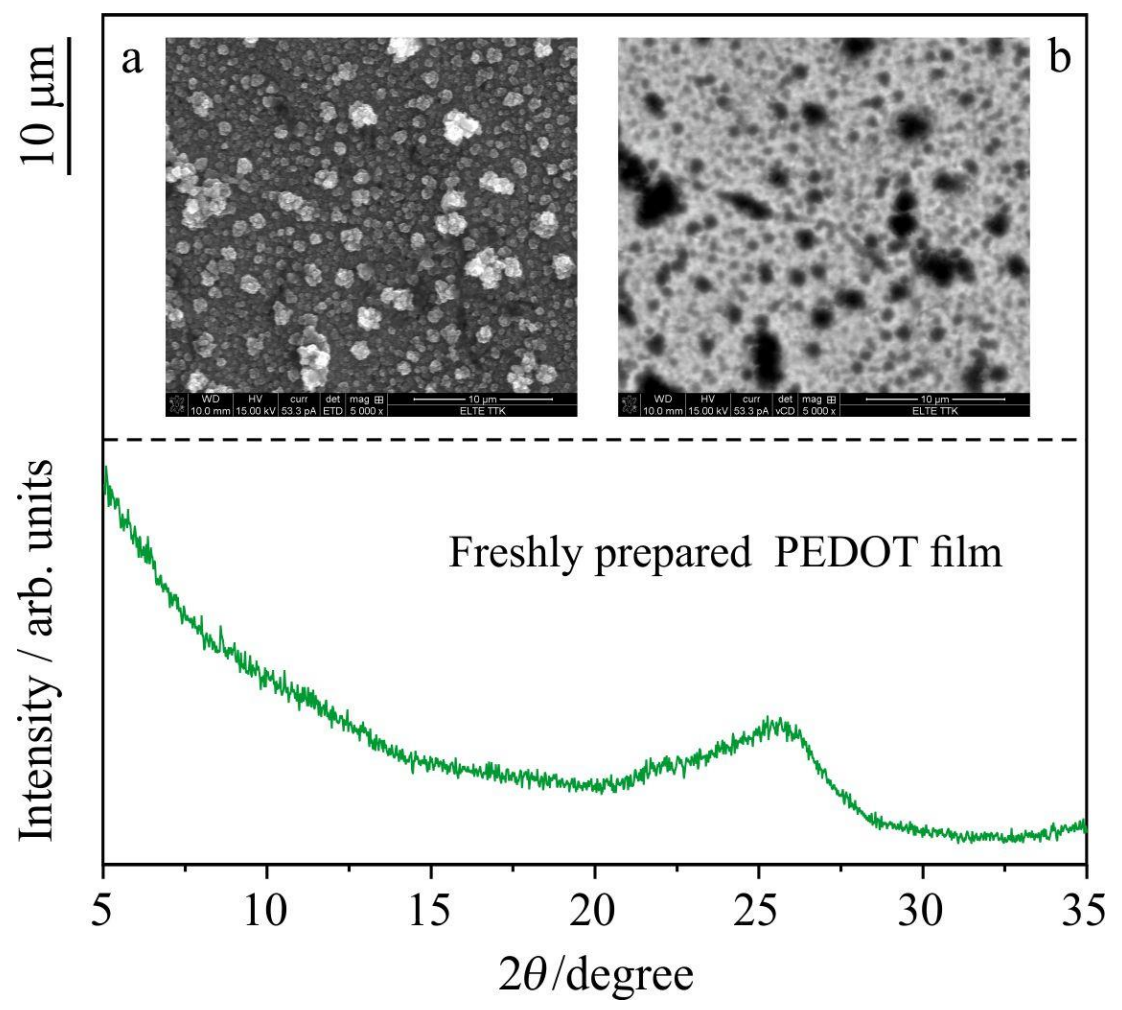

Figure 4. Structure of the freshly prepared PEDOT film: X-ray diffractogram. Inserts: (a) SEM image using secondary electrons. (b) The corresponding backscattered SEM image taken from the same area. The length of the vertical black bar left to the images corresponds to $10 \mu \mathrm{m}$.

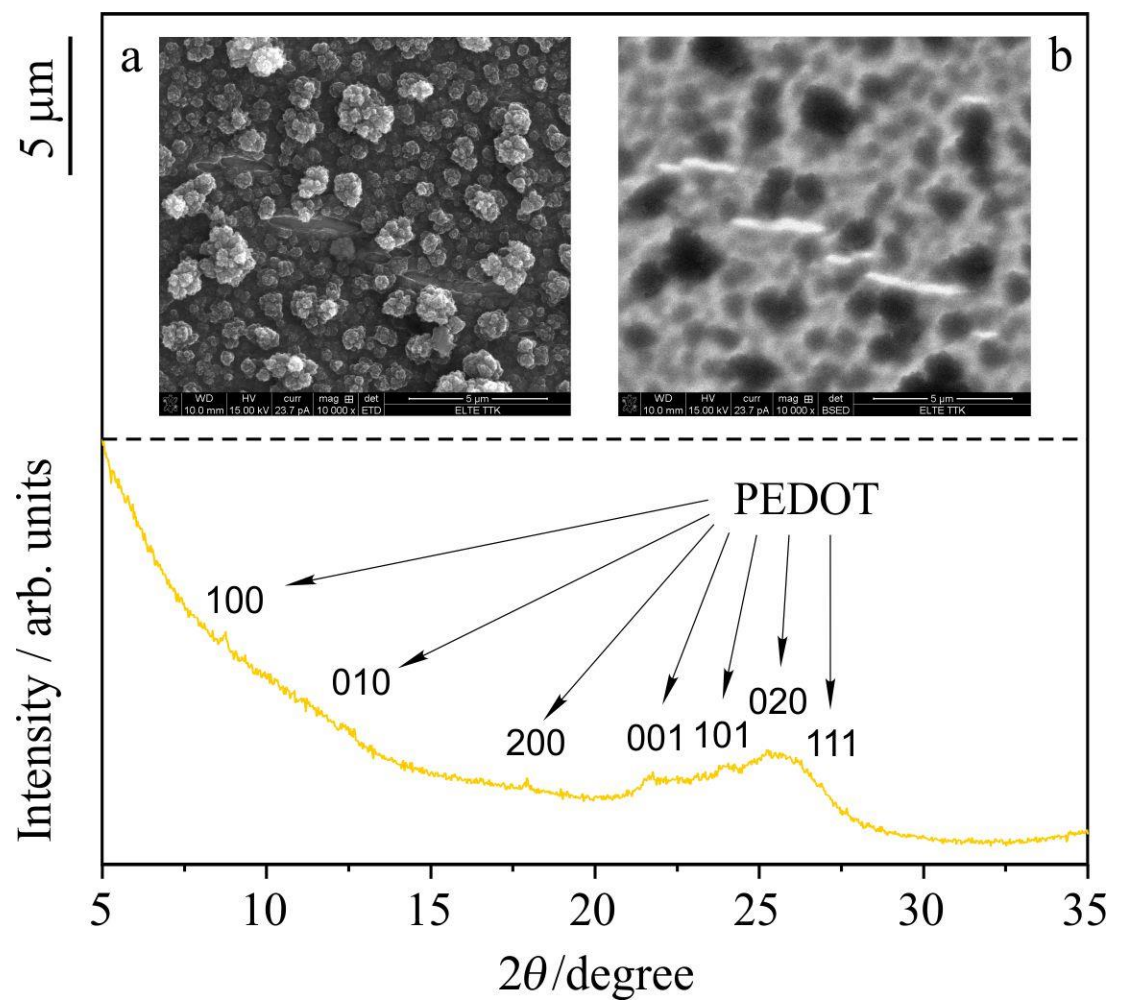

Figure 5. Structure of the oxidized PEDOT film after time interval " $A$ " in Fig 2a: $X$-ray diffractogram. Inserts: (a) SEM image using secondary electrons. (b) The corresponding backscattered SEM image taken from the same area. The length of the vertical black bar left to the images corresponds to $5 \mu \mathrm{m}$. 


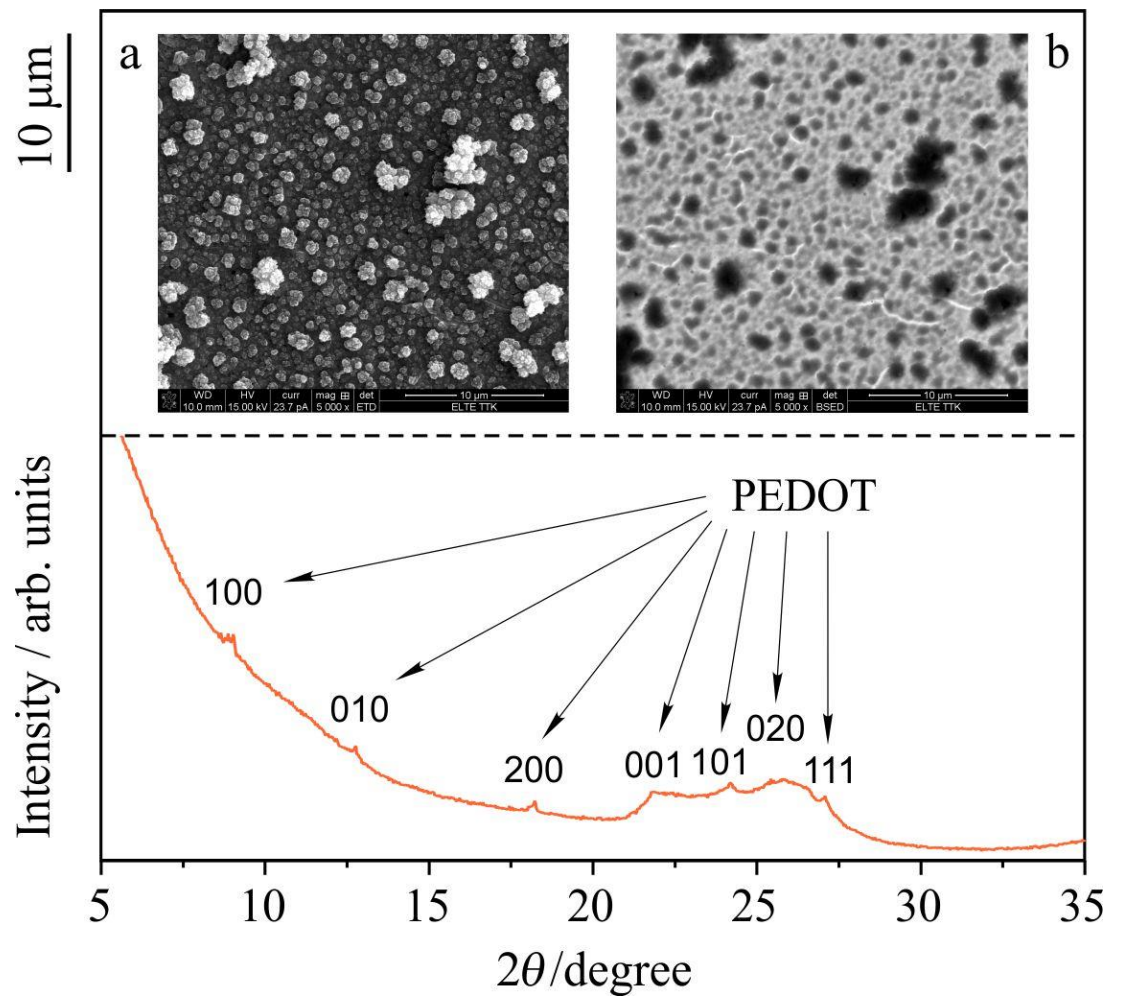

Figure 6. Structure of the oxidized PEDOT film, recorded after time interval " $B$ " in Fig 2a: X-ray diffractogram. Inserts: (a) SEM image using secondary electrons. (b) The corresponding backscattered SEM image taken from the same area. The length of the vertical black bar left to the images corresponds to $10 \mu \mathrm{m}$.

After oxidation in the interval " $\mathrm{C}$ " well-separated X-ray diffraction peaks are observed (Fig. 7). The diffraction peaks of crystalline PEDOT were indexed according to previous studies [58,59]. These works identified this phase as orthorhombic structure.

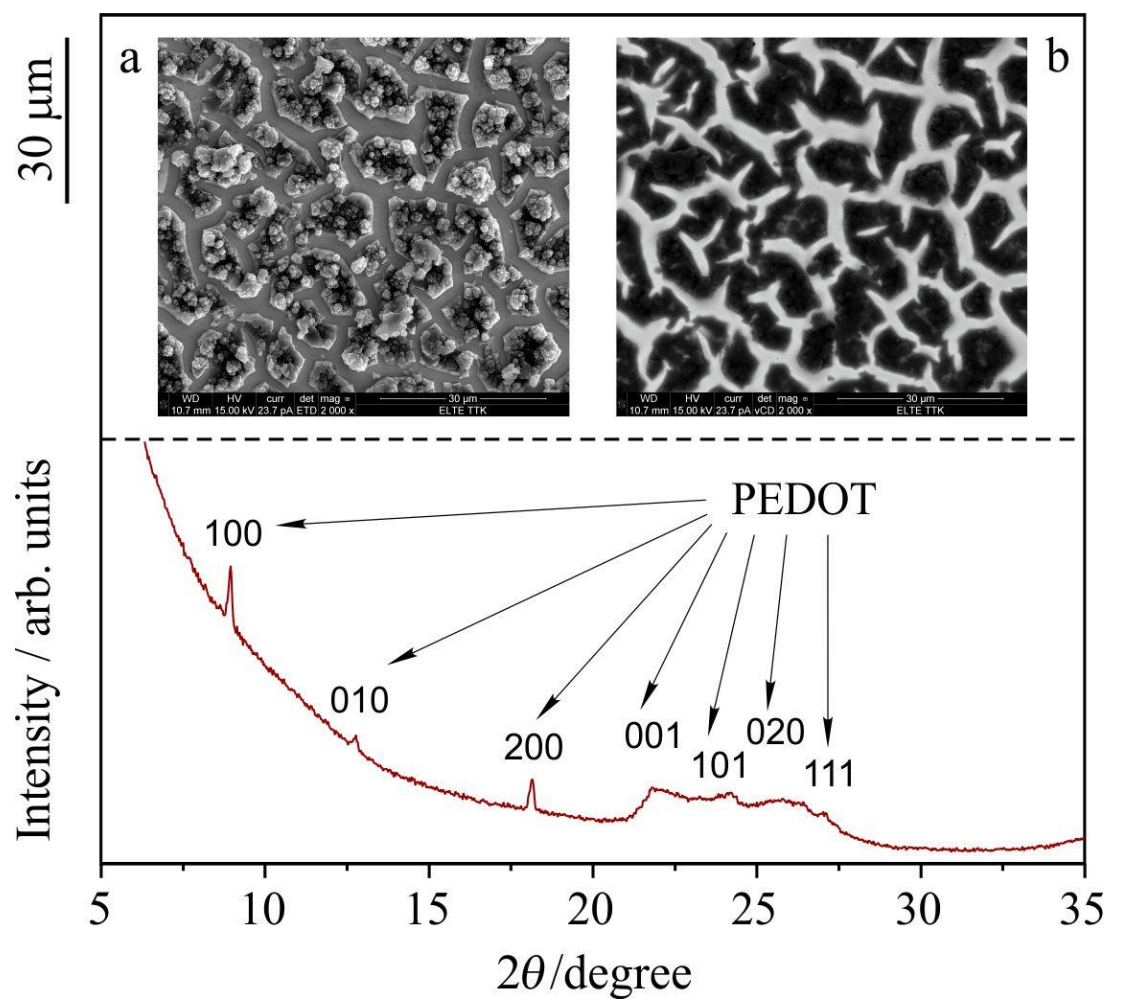

Figure 7. Structure of the oxidized PEDOT film, recorded after time interval " $\mathrm{C}$ " in Fig 2a: X-ray diffractogram. Inserts: (a) SEM image using secondary electrons. (b) The corresponding backscattered SEM image taken from the same area. The length of the vertical black bar left to the images corresponds to $10 \mu \mathrm{m}$. 
The best agreement between the theoretical orthorhombic and the experimental peak positions was obtained by selecting the following values for the three lattice parameters: $a=0.980 \mathrm{~nm}, b=0.690 \mathrm{~nm}, c=0.405 \mathrm{~nm}$. The value of $b$ is very close to the lattice constant $(b=0.679 \mathrm{~nm})$ determined from reflection 020 in a previous study [59]. However, it should be noted that the values of the lattice parameters of PEDOT are very sensitive to the type of counter ion as revealed in Table 2.1 of Ref. [59]. The diffraction peaks of PEDOT became sharper and more intensive due to electrochemical treatment. This indicates that besides the degradation of the PEDOT film its crystallinity was gradually improved with increasing the number of oxidation cycles. In the SEM micrographs the cauliflower structure is still present, but the film forms islands on the surface of the substrate. The width of the crevices shown in Fig. 7a is about 2-3 $\mu \mathrm{m}$. According to the backscattered SEM micrographs (Fig. 7b) the crevices form a widespread network. EDX analysis proved that only $\mathrm{Au}$ is present at the bottom of the grooves. As we mentioned above there is a stress change in the polymer layer during overoxidation. This change may result in the formation of structures similar to those often found on the surface of asphalt pavement (Figs. 8a and $8 \mathrm{~b}$ ). It is known that stress change due to the thermal expansion (and/or other processes e.g. evaporating of volatile contents, freezing of water) can cause "alligatoring" (interconnected cracks in the asphalt surface).)
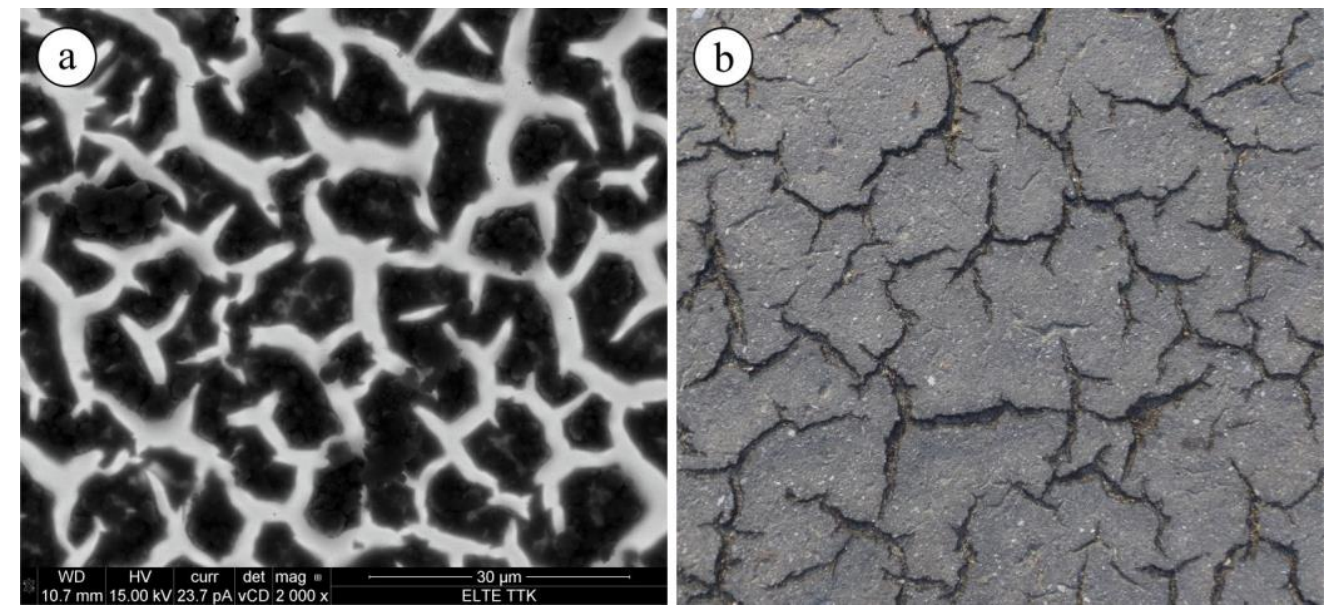

Figure 8. Similar structures (a) Backscattered SEM image of the oxidized PEDOT. The length of the horizontal white bar below the image corresponds to $30 \mu \mathrm{m}$. (b) Picture of asphalt at Vácrátót square, Budapest, Hungary (coordinates 47.577272 N, 19.125732 E).

\section{Conclusions}

The above experimental results support the mechanistic picture, according to which the originally compact and strongly adherent polymer films undergo structural changes during electrochemical degradation, and agree with earlier observations that the porosity of the film increases progressively during the degradation process. It can be seen from the SEM images of overoxidized Au|PEDOT that the degradation process induces only a partial delamination of the polymer film from the underlying metal. However, the charge transfer process at the metal/film interface is somewhat more hindered in case of the degraded film. Apparently, the formation of quite well-ordered arrays of islands and trench-like structures is a common occurrence during overoxidation of PEDOT films. In the XRD patterns, the diffraction peaks became sharper and more intensive during the subsequent oxidation cycles indicating an increase in the degree of crystallinity of the polymer. 
The results also suggest that, besides the increase in the porosity, the generation of sites with novel catalytic and binding properties may also influence the sensitivity and specificity of conducting polymer-based sensors for the analysis of organic and inorganic substances.

Acknowledgements: Financial support from the Hungarian Scientific Research Fund (grants No. $K 109021$ and $K 109036)$ are gratefully acknowledged. The authors thank Prof. K. Havancsák, Prof. Z. Dankházi and Prof. G. Varga for the SEM measurements, and for helpful discussions: S. Vesztergom gratefully acknowledges the support of the European Union and the State of Hungary, as well as of the European Social Fund in the framework of TÁMOP 4.2.4.A/1-11-1-2012-0001 "National Excellence Program".

\section{References}

[1] C. Kvarnström, Conducting Polymers, in: Electrochemical Dictionary, 2nd edn., A.J. Bard, G. Inzelt, F. Scholz, Eds., Springer, Heidelberg, Germany, 2012

[2] G. Inzelt, Conducting polymers. A new era in electrochemistry, 2nd edn. in: Monographs in electrochemistry, F. Scholz Ed., Springer, Berlin Heidelberg, Germany, 2012

[3] U. Lang, N. Naujoks, J. Dual, Synthetic Met 159 (2009) 473-479

[4] G. Inzelt, in Electroanalytical chemistry, vol. 18. A.J. Bard Ed., Marcel Dekker, New York, USA, 1994

[5] G.F. Wang, X.M. Tao, R.X. Wang, Nanotechnology 19 (2008) 145201-145202

[6] G. Inzelt, A. Pineri, J.W. Schultze, M.A. Vorotyntsev Electrochim. Acta 45 (2000) 2403-2421

[7] M.R. Lilliedala, A.J. Medforda, M.V. Madsena, K. Norrmana, F.C. Krebs, Sol. Energ. Mat. Sol. C. 94 (2010) 2018-2031

[8] E. Nasybulin, S. Wei, M. Cox, I. Kymissis, K. Levon, J. Phys. Chem. C 115 (2011) 4307-4314

[9] J.C. Scott, Science 304 (2004) 62-63

[10] S. Möller, C. Perlov, W. Jackson, C. Taussig, S.R. Forrest, Nature 426 (2003) 166-169

[11] X. Cui, D.C. Martin, Sensor. Actuat. B-Chem 89 (2003) 92-102

[12] M. Vázquez, P. Danielsson, J. Bobacka, A. Lewenstam, A. Ivaska, Sensor. Actuat. B-Chem 97 (2004) 182-189

[13] J. Bobacka, Anal. Chem. 71 (1999) 4932-4937

[14] J.F. Drillet, R. Dittmeyer, K. Jüttner, L. Li, K.M. Mangold, Fuel Cells 6 (2006) 432-438

[15] J.F. Drillet, R. Dittmeyer, K. Jüttner J. Appl. Electrochem. 37 (2007) 1219-1226

[16] C. Kvarnström, Poly(thiophene), in: Electrochemical Dictionary, 2nd edn., A.J. Bard, G. Inzelt, F. Scholz, Eds., Springer, Heidelberg, Germany, 2012

[17] J. Bobacka, A. Lewenstam, A. Ivaska, J. Electroanal. Chem. 489 (2000) 17-27

[18] H. Yamato, M. Ohwa, W. Wernet, J. Electroanal. Chem. 397 (1995) 163-170

[19] N. Sakmeche, S. Aeiyach, J.J. Aaron, M. Jouini, J.C. Lacroix, P.C. Lacaze, Langmuir 15 (1999) 2566-2574

[20] A. Zykwinska, W. Domagala, B. Pilawa, M. Lapkowski, Electrochim. Acta 50 (2005) 16251633

[21] M. Ujvári, M. Takács, S. Vesztergom, F. Bazsó, F. Ujhelyi, G.G. Láng, J. Solid. State. Electrochem. 15 (2011) 2341-2349

[22] G.G. Láng, M. Ujvári, F. Bazsó, S. Vesztergom, F. Ujhelyi, Electrochim. Acta 73 (2012) 59-69

[23] G.G. Láng, C. Barbero, Laser techniques for the study of electrode processes, in: Monographs in electrochemistry, F. Scholz Ed., Springer, Berlin Heidelberg, Germany, 2012

[24] J. Li, X-Q. Lin, Sens. Actuators B 124 (2007) 486-493

[25] D.C. Martin, J. Wu, C.M. Shaw, Z. King, S.A. Spanninga, S. Richardson-Burns, J. Hendricks, J. Yang, Polym Rev 50 (2010) 340-384 
[26] Z. Zhuang, J. Li, R. Xu, D. Xiao, Int. J. Electrochem. Sci. 6 (2011) 2149-2161

[27] M. Irimia-Vladu, Chem. Soc. Rev. 43 (2014) 588-610

[28] M.R. Majidi, A. Jouyban, K. Asadpour-Zeynali, Electrochim. Acta 52 (2007) 6248-6253

[29] X. Tu, Q. Xie, S. Jiang, S. Yao, Biosens. Bioelectron. 22 (2007) 2819-2826

[30] J. Wen, L. Zhou, L. Jin, X. Cao, B.-C. Ye, J. Chromatogr. B 877 (2009) 1793-1798

[31] Y. Li, P. Wang, L. Wang, X. Lin, Biosens. Bioelectron. 22 (2007) 3120-3125

[32] A. Boateng, F. Iraque, A. Brajter-Toth, Electroanalysis 25 (2013) 345-355

[33] T.A. Bendikov, T.C. Harmon, Anal. Chim. Acta 551 (2005) 30-36

[34] J.-M. Lin, Y.-L. Su, W.-T. Chang, W.-Y. Su, S.-H. Cheng, Electrochim. Acta 149 (2014) 65-75

[35] A. Boateng, R. Cohen-Shohet, A. Brajter-Toth, Electrochim. Acta 56 (2011) 7651-7658

[36] M. Ujvári, J. Gubicza, V. Kondratiev, K.J. Szekeres, G.G. Láng J. Solid State Electrochem. 19 (2015) 1247-1252

[37] A. Stoyanova, V. Tsakova, J. Solid State Electrochem. 14 (2010) 1947-1955

[38] W. Poppendieck, K.P. Hoffmann, in: ECIFMBE 2008, IFCMBE Proceedings 22, J. Vander Sloten, P. Verdonck, M. Nyssen, J. Haueisen, Eds., Springer-Verlag Berlin, Heidelberg, Germany, 2009, pp. 2409-2412

[39] Q. Pei, O. Inganaes, J. Phys. Chem. 96 (1992) 10507-10514

[40] Q. Pei, O. Inganaes, J. Phys. Chem. 97 (1993) 6034-6041

[41] V. Tabard-Cossa, M. Godin, P. Grütter, I. Burgess, R.B. Lennox, J. Phys Chem. B 109 (2005) 17531-17537

[42] G.G. Láng, in: Electrochemical Dictionary, A.J. Bard, G. Inzelt, F. Scholz, Eds., Springer, Berlin, Germany, 2008, pp. 43-44

[43] G.G. Láng, N.S. Sas, S. Vesztergom, Chem. Biochem. Eng. Q. 23 (2009) 1-9

[44] K. Ueno, M. Seo, J. Electrochem. Soc. 146 (1999) 1496-1499

[45] S.N. Sahu, J. Scarminio, F. Decker, J. Electrochem. Soc. 137 (1990) 1150-1154

[46] S. Cattarin, E. Pantano, F. Decker, Electrochem. Commun. 1 (1999) 483-487

[47] S. Cattarin, F. Decker, D. Dini, B. Margesin, J. Electroanal. Chem. 474 (1999) 182-187

[48] R. Raiteri, H.-J. Butt, M. Grattarola, Scanning Microscopy 12 (1998) 243-251

[49] O.E. Kongstein, U. Bertocci, G.R. Stafford, J. Electrochem. Soc. 152 (2005) C116-C123

[50] G.R. Stafford, U. Bertocci, J. Phys. Chem. B 110 (2006) 15493-15498

[51] M. Godin, V. Tabard-Cossa, Y. Miyahara, T. Monga, P.J. Williams, L.Y. Beaulieu, B. Lennox, R. Bruce, P. Grütter, Nanotech. 21 (2010) 075501 (8pp)

[52] G.G. Stoney, Proc Roy. Soc. London A32 (1909) 172-175

[53] G.G. Láng, K. Ueno, M. Ujvári, M. Seo, J. Phys. Chem. B 104 (2000) 2785-2789

[54] G.G. Láng, M. Seo, J. Electroanal. Chem. 490 (2000) 98-101

[55] G.G. Láng, J. Appl. Phys. 107 (2010) 116104-1-116104-3

[56] H.P. Klug, L.E. Alexander, X-ray diffraction procedures for polycrystalline and amorphous materials, John Wiley and Sons, New York, USA, 1974

[57] L.F.Q.P. Marchesi, F.R. Simoes, L.A. Pocrifka, E.C. Pereira, J. Phys. Chem. B 115 (2011) 95709575

[58] J. Wu, Morphology of Poly(3,4-ethylene dioxythiophene) (PEDOT) Thin Films, Crystals, Cubic Phases, Fibers and Tubes, PhD dissertation, The University of Michigan, 2011

[59] T. Takano, H. Masunaga, A. Fujiwara, H. Okuzaki, T. Sasaki, Macromolecules 45 (2012) 3859-3865

(C) 2016 by the authors; licensee IAPC, Zagreb, Croatia. This article is an open-access article distributed under the terms and conditions of the Creative Commons Attribution license (http://creativecommons.org/licenses/by/4.0/) (cc) Br 